\title{
A Cotton-Fiber-Associated Cyclin-Dependent Kinase A Gene: Characterization and Chromosomal Location
}

\author{
Weifan Gao, ${ }^{1}$ Sukumar Saha, ${ }^{2}$ Din-Pow Ma, ${ }^{1}$ Yufang Guo, ${ }^{3}$ \\ Johnie N. Jenkins, ${ }^{2}$ and David M. Stelly ${ }^{4}$ \\ ${ }^{1}$ Department of Biochemistry, Molecular Biology, Entomology, and Plant Pathology, Mississippi State University, \\ Mississippi State, MS 39762, USA \\ ${ }^{2}$ USDA/ARS Crop Science Research Laboratory, P.O. Box 5367, Mississippi State, MS 39762, USA \\ ${ }^{3}$ Department of Plant and Soil Sciences, Mississippi State University, Mississippi State, MS 39762, USA \\ ${ }^{4}$ Department of Soil and Crop Sciences, Texas A\&M University, College Station, TX 77845, USA
}

Correspondence should be addressed to Din-Pow Ma, dm1@ra.msstate.edu

Received 9 March 2012; Accepted 28 April 2012

Academic Editor: Akhilesh Kumar Tyagi

Copyright (C) 2012 Weifan Gao et al. This is an open access article distributed under the Creative Commons Attribution License, which permits unrestricted use, distribution, and reproduction in any medium, provided the original work is properly cited.

\begin{abstract}
A cotton fiber cDNA and its genomic sequences encoding an A-type cyclin-dependent kinase (GhCDKA) were cloned and characterized. The encoded GhCDKA protein contains the conserved cyclin-binding, ATP binding, and catalytic domains. Northern blot and RT-PCR analysis revealed that the GhCDKA transcript was high in 5-10 DPA fibers, moderate in 15 and 20 DPA fibers and roots, and low in flowers and leaves. GhCDKA protein levels in fibers increased from 5-15 DPA, peaked at 15 DPA, and decreased from 15 t0 20 DPA. The differential expression of GhCDKA suggested that the gene might play an important role in fiber development. The GhCDKA sequence data was used to develop single nucleotide polymorphism (SNP) markers specific for the CDKA gene in cotton. A primer specific to one of the SNPs was used to locate the CDKA gene to chromosome 16 by deletion analysis using a series of hypoaneuploid interspecific hybrids.
\end{abstract}

\section{Introduction}

Cotton fibers are unicellular seed trichomes differentiated from the outer integument of a developing seed. The regulation of cell division is thus an important aspect of fiber initiation and development. About $25 \%$ of commercial cotton ovule epidermal cells stops division and develops to produce fibers [1]. It has been reported that the cell cycle in fiber cells is arrested in the G1 phase during the early stages of fiber development [2]. A central role in the regulation of the cell division is played by cyclin-dependent kinases (CDKs) and their regulatory cyclin subunits [3-5]. Eleven types of cyclins (A, B, C, D, H, CycJ18, L, T, U, SDS (solo dancers), and P) have been identified in plants $[6,7]$. Plant CDKs, identified in 23 species of algae, gymnosperms, and angiosperms, contain three functional domains: an ATP-binding domain, a cyclinbinding domain, and a catalytic domain. They are classified into five types (A, B, C, D, and E) based on their sequence differences in the cyclin-binding domain [8]. The A-type CDK (CDKA) proteins are characterized by the presence of the PSTAIRE motif, which is essential for cyclin binding [9]. Plant CDKAs, but not CDKBs, have been shown to complement yeast CDK mutants [10-13], suggesting that plant CDKAs are functional homologues of the yeast CDK. Plant CDKAs not only control cell cycle progression from the $\mathrm{G} 1$ to $S$ phase and from the $\mathrm{G} 2$ to $\mathrm{M}$ phase $[5,14]$ but also participate in cell proliferation and maintenance of cell division competence in differentiated tissues during development [15]. Since the CDKA gene is expressed in both dividing and differential tissues [15, 16], it has been suggested that the gene is involved in both cell division and differentiation $[17,18]$.

To dissect the possible functional role of CDKA in fiber cell differentiation and development, we have cloned and characterized a fiber CDKA cDNA and its corresponding genomic sequences. The expression levels of the CDKA transcript and the CDKA protein were also determined in elongating cotton fibers from 5 to 20 DPA ovules and other tissues. The CDKA sequence data was then used to develop single nucleotide polymorphism (SNP) markers specific for the 
CDKA gene(s) in cotton. Lastly, a primer specific to one of the SNPs was used with single primer extension technology to locate the CDKA gene to chromosome 16 by deletion analysis using a series of hypoaneuploid interspecific hybrids.

\section{Materials and Methods}

2.1. Cloning of Fiber GhCDKA cDNA. Two degenerate primers (CDK1: 5'-ATHGGDGARGGHACHTAYGG-3' and CDK2: 5'-CKATCWATCARYARRTTYTG-3') (H: A + $\mathrm{C}+\mathrm{T}, \mathrm{D}: \mathrm{A}+\mathrm{G}+\mathrm{T}, \mathrm{R}: \mathrm{A}+\mathrm{G}, \mathrm{Y}: \mathrm{C}+\mathrm{T}, \mathrm{K}: \mathrm{G}+$ $\mathrm{T}, \mathrm{W}: \mathrm{A}+\mathrm{T}$ ) designed from the conserved ATP-binding and catalytic domains of plant CDKA genes were used for PCR to amplify cDNA with homology to the CDKA gene using total cDNA from a cotton (Gossypium hirsutum L. cv. DES119) fiber cDNA library as template. The cDNA library was constructed using 10 DPA (days post-anthesis) fiber RNA with a Marathon cDNA amplification kit (BD Biosciences, San Jose, CA, USA). A 383 bp DNA fragment was amplified, purified using a QIAEX II gel extraction kit (Qiagen), cloned into pGEM-T Easy Vector (Promega), and sequenced with an ABI PRISM 310 Genetic Analyzer. The DNA sequencing data was analyzed using the BLAST program (NCBI) and LASERGENE software (DNASTAR). Analysis of the sequencing data showed that the $383 \mathrm{bp}$ DNA fragment encoded an A-type CDK. Two gene specific primers CDKC-1 (5'GGCGTTGTTTATAAGGCTCGTGATCGTG$\left.3^{\prime}\right)$ and CDKC-2 (5'CATTCCTTTATCAAATTCTCCGTGGTG-3') were designed from the $383 \mathrm{bp}$ DNA fragment and used to amplify a full-length GhCDKA cDNA by the Rapid Amplification of cDNA Ends (RACE) method with the Marathon cDNA Amplification kit. In the $3^{\prime}$ RACE reaction, CDKC-1 and the adaptor primer AP1 (5'-CCATCCTAATACGACTCACTATAGGGC-3' $10 \mu \mathrm{M})$ were used in the first PCR, and CDKC-2 and the adaptor primer AP2 (5'-ACTCACTATAGGGCTCGAGCGGC-3') were used in the second (nested) PCR. The $5^{\prime}$ RACEs were also performed as $3^{\prime}$ RACEs, except that primers CDK5-1 (5' GACACTTTCTCAGGAAGATAGTTG- $3^{\prime}$ ) and CDKC-3 (5'-CCCTATGAGAGTGACAATAAGCAATG-3') were used in the first and second RACE amplifications, respectively. A full-length GhCDKA cDNA was assembled using the $5^{\prime}$ and $3^{\prime}$ RACE products and subsequently confirmed by PCR using $P f u$ DNA polymerase (Stratagene).

2.2. Isolation of the Genomic Sequence of the GhCDKA Gene. Two primers CDKC-1 and CDK5-1 were used in LA (long and accurate) PCR to amplify DES119 genomic DNA with the Takara LA PCR kit ver.2.1. The PCR was conducted with an initial denaturation at $94^{\circ} \mathrm{C}$ for $4 \mathrm{~min}$, followed by 30 cycles at $94^{\circ} \mathrm{C}$ for $30 \mathrm{sec}$ and $68^{\circ} \mathrm{C}$ for $4 \mathrm{~min}$ and a final extension at $68^{\circ} \mathrm{C}$ for $5 \mathrm{~min}$. A $7547 \mathrm{bp}$ DNA fragment containing the GhCDKA gene was amplified. The PCR product was gel purified and cloned, and both DNA strands are sequenced as described above.

The $5^{\prime}$ and $3^{\prime}$ flanking regions of the GhCDKA gene were amplified using a PCR-based genomic DNA walking method and inverse PCR. Genomic walking was conducted by amplifying the adaptor-ligated genomic libraries using genespecific primers GSR-1 (5'-TGAGTTGTGCAGTGAAGTGCATTG-3') and GSR-2 (5'-CTCTAATTGCAGTGCTAGGTACAC- $3^{\prime}$ ). The self-ligated genomic DNA (previously restricted with Hind III) was used as template in the inverse PCR amplification with primers GSF (5'-TCTGGAAGCGGAAAGAAGCA-3') and GSR-1 and LA Taq DNA polymerase (see Figure 1 in Supplementary Material available online at doi:10.1155/2012/613812.)

\subsection{Expression Analyses of the GhCDKA Gene. Total RNA} $(10 \mu \mathrm{g})$ isolated from various cotton tissues were electrophoresed in a formaldehyde/agarose gel, transferred onto a nylon membrane, and fixed by UV-crosslinking. A $618 \mathrm{bp}$ DNA fragment corresponding to the C-terminal and $3{ }^{\prime}$-UTR region of the GhCDKA cDNA was amplified by PCR using two primers CDKC-2 and CDK5-1, labeled with $\left[\alpha_{-}{ }^{32} \mathrm{P}\right]$ $\mathrm{dCTP}$ with the random priming labeling method, and used as a probe for Northern hybridization. After hybridization, the membrane was stringently washed and exposed to X-ray film for autoradiography. The relative GhCDKA transcript levels were determined by the ratio of radioactive intensity of hybridized band of the $1.2 \mathrm{~kb}$ GhCDKA mRNA to the EtBr stained 28S rRNA using the program of Scion Image for Windows (Scion Corporation). The GhCDKA transcript level was also determined by RT-PCR. First strand cDNA, labeled by $\left[\alpha^{32} \mathrm{P}\right]$ dCTP, was synthesized with SuperScript II reverse transcriptase (Invitrogen) using oligo-dT primer and total RNA $(2 \mu \mathrm{g})$ isolated from flowers, leaves, roots, and 5, 10 , and 15 DPA fibers. An equal amount of the synthesized first strand cDNA (based on scintillation counting) from different samples was serially diluted to $1 \mathrm{x}, 5 \mathrm{x}, 10 \mathrm{x}, 20 \mathrm{x}$ with sterile distilled water and used as template for PCR amplification with primers CDKC-2 and CDK5-1. Five microliters of the PCR products was analyzed by electrophoresis in a $1 \%$ agarose gel.

For Western analysis, $70 \mu \mathrm{g}$ of total protein extracted from cotton flowers, leaves, and fibers $(5,10,15$, and 20 DPA) with a modified method of Barent and Elthon [19] was vacuum dried and resuspended in SDS-PAGE sample buffer (12 mM Tris-HCl, pH 6.8, 5\% (v/v) glycerol, 0.4\% (w/v) SDS, $1 \%(\mathrm{v} / \mathrm{v}) \quad \beta$-mercaptoethanol, $0.02 \%(\mathrm{w} / \mathrm{v})$ bromophenol blue). The samples were heat denatured, separated by $12 \%$ SDS-PAGE, and transferred onto a nitrocellulose membrane. Immunodetection of the GhCDKA protein was carried out with an ECL Western blotting system (GE Healthcare) using rabbit anti-PSTAIRE (Santa Cruz Biotechnology) as primary antibody and anti-rabbit IgG-horseradish peroxidase conjugate (GE Healthcare) as secondary antibody.

2.4. SNP Analyses and Chromosomal Location of the GhCDKA Gene. Genomic DNAs were extracted from young leaves of CMD-01 (TM-1, G. hirsutum), CMD-02 (3-79, G. barbadense), CMD11 (G. tomentosum), CMD-3 (G. arboreum), and CMD-5 (G. raimondii) using a DNeasy Plant mini kit (Qiagen). These Gossypium genotypes have been widely used for the screening and preliminary characterization of cotton microsatellite markers [20]. The genomic DNA samples 
were amplified by $p f u$ DNA polymerase with two primers (CDKP3, 5'-GGCTGGTTATGTTGTGGTAGTACTG-3' (nt-913 to -889)); and CDKP4, 5' -GTGCAGCTCCACCAGACGAGAAG-3' (nt-1 to -23)) designed from $5^{\prime}$-flanking region upstream of the start codon ATG of the GhCDKA gene. The amplified PCR products were gel purified, cloned, and then sequenced. The sequence of DES 119 (G. hirsutum) was then aligned with those of TM-1 (G. hirsutum), 3-79 (G. barbadense), and CMD11 (G. tomentosum) using the Clustal method (DNASTAR software) for SNP identification.

The chromosomal location of the CDKA gene was determined by following the overall strategy of Liu et al. [21] using hypoaneuploid chromosome substitution stocks $\left(\mathrm{BC}_{0} \mathrm{~F}_{1}\right)$ and a euploid $\mathrm{BC}_{5} \mathrm{~F}_{1} \mathrm{~S}_{1}$ chromosome substitution line of TM1 disomic for the chromosome 16 of G. barbadense [22]. The monotelodisomics included telosomes $1 \mathrm{Lo}, 2 \mathrm{Lo}, 2 \mathrm{sh}, 3 \mathrm{Lo}$, $3 \mathrm{sh}, 4 \mathrm{sh}, 5 \mathrm{Lo}, 6 \mathrm{Lo}, 7 \mathrm{Lo}, 7 \mathrm{sh}$, 9Lo, 11Lo, 14Lo, 15Lo, 15sh, $16 \mathrm{sh}, 16 \mathrm{Lo}, 18 \mathrm{Lo}, 18 \mathrm{sh}, 20 \mathrm{Lo}, 22 \mathrm{sh}, 25 \mathrm{Lo}$, and $26 \mathrm{sh}$, where Lo $=$ long arm and $\mathrm{sh}=$ short arm. Monosomes included chromosomes 1, 2, 3, 4, 6, 7, 9, 10, 12, 17, 18, 20, 23, and 25 . Each interspecific hybrid is expectedly heterozygous for all polymorphisms between the two parents, except those rendered hemizygous by the monosome- or telosome-defined deficiency. At hemizygous loci, the G. hirsutum allele is expectedly absent and only the G. barbadense allele is present. The telosomes expectedly lack all or most of the opposing arm, for example, an $\mathrm{F}_{1}$ plant monotelodisomic for 6Lo will be hemizygous for G. barbadense polymorphisms in the short arm distal to the telosome breakpoint. We used cytologically identified BC5-derived inbred euploid backcross substitution line for chromosome 16 of G. barbadense in G. hirsutum in lieu of an available monosomic $\mathrm{BC}_{0} \mathrm{~F}_{1}$ plant. The disomic chromosome substitution line is euploid but has one pair of chromosome 16 from G. barbadense line 3-79, whereas the other 25 chromosome pairs are largely or completely derived from TM-1.

A SNP primer (5'-GCCCAACTATAGAAATGAAA- $\left.3^{\prime}\right)$ designed based on a single nucleotide differences in the sequences between the lines among the three Gossypium species (G. hirsutum, G. barbadense, and G. tomentosum) was used to screen SNP markers of the genetic stocks with the ABI Prism SNaPshot multiplex kit following the method of Buriev et al. [23]. Briefly, the $p f u$-amplified PCR products were incubated with SAP and Exo I (5 units of SAP and 2 units of Exo I for $15 \mu \mathrm{L}$ PCR product) at $37^{\circ} \mathrm{C}$ for $1 \mathrm{hr}$ followed by $75^{\circ} \mathrm{C}$ for $15 \mathrm{~min}$. The PCR mixture contained $5 \mu \mathrm{L}$ of SnaPshot Multiplex Ready Reaction Mix, $3 \mu \mathrm{L}$ of purified PCR product, $1 \mu \mathrm{L}$ of SNP primer $(10 \mu \mathrm{M})$, and $1 \mu \mathrm{L}$ of distilled water. The thermal cycle reaction was carried out with 25 cycles of $96^{\circ} \mathrm{C}, 10 \mathrm{sec}, 50^{\circ} \mathrm{C}, 5 \mathrm{sec}$, and $60^{\circ} \mathrm{C}$, $30 \mathrm{sec}$. After treated with SAP, $0.5 \mu \mathrm{L}$ of SnaPshot product was mixed with $0.5 \mu \mathrm{L}$ of size standard and $9 \mu \mathrm{L}$ of $\mathrm{Hi}-\mathrm{Di}$ formamide denatured at $95^{\circ} \mathrm{C}$ for $5 \mathrm{~min}$ and then run onto a 3100 Genetic Analyzer (Applied Biosystems).

\section{Results}

3.1. Cloning and Characterization of GhCDKA Gene. A 383 bp DNA fragment was amplified by PCR from a 10
DPA cotton fiber cDNA library using two degenerate primers designed from the conserved ATP-binding and catalytic domains of plant A-type CDK genes. BLAST searching in GenBank Databases indicated that the $383 \mathrm{bp}$ cDNA encoded a protein with extensive homology to plant Atype CDKs. A full-length fiber CDKA cDNA (1211 bp), named $G h C D K A$, was subsequently cloned by $5^{\prime}$ and $3^{\prime}$ RACEs using gene-specific primers designed from the $383 \mathrm{bp}$ fragment. The GhCDKA gene and its $5^{\prime}$ flanking region (9675 bp) (Supplementary Figure 1) were cloned by genomic walking and inverse PCR. GhCDKA encodes a protein of 294 aa with a predicted molecular mass of $34 \mathrm{kDa}$. The protein contained three conserved functional domains of CDK proteins: an ATP-binding domain, a cyclin-binding domain, and a catalytic domain. The GhCDKA protein also had the conserved PSTAIRE motif found in A-type CDKs in the cyclin binding domain. Comparisons of the cDNA and genomic sequences revealed that the GhCDKA gene contained 9 exons and 8 introns with 7 introns located within the coding region and one intron at the $5^{\prime}$ UTR region (Supplementary Figure 1). The GhCDKA gene had the same number and sizes of exons and the same number of introns as the Arabidopsis CDKA; 1 gene (AtCDKA; 1, Genbank GI: 18408695), but the sizes of introns were much larger than those of Arabidopsis (Figure 1). The alignment of aa sequences of CDKA proteins from cotton (GhCDKA) and ten other plant species, including Populus tremula $\mathrm{x} P$ Populus tremuloides (PtCDKA), Helianthus annuus (HaCDKA), Picea abies (PaCDKA), Solanum lycopersicon (LeCDKA; 1), Pinus contorta (PncCDKA), Chenopodium rubrum (CrCDKA), Helianthus tuberosus (HtCDKA), Antirrhinum majus (AmCDKA), Nicotiana tobacum (NtCDKA), and Arabidopsis thaliana (AtCDKA; 1) revealed that GhCDKA was $91.5-94.2 \%$ identical to PtCDKA, PaCDKA, HaCDKA, LeCDKA; 1, CrCDKA, PncCDKA, HtCDKA, AmCDKA, and NtCDK and $86.7 \%$ identical to AtCDKA; 1 (data not shown). Phylogenetic analysis of aa sequences of the 11 plant CDKA proteins indicated that GhCDKA was distant to AtCDKA; 1 but closer to the other nine CDKAs (Figure 2).

3.2. Expression of the GhCDKA Gene. The mRNA abundance of the GhCDKA gene was analyzed by Northern blot with total RNA isolated from flowers, leaves, roots, and fibers at different developmental stages $(5,10,15$, and 20 DPA). The 618 bp DNA fragment corresponding to the C-terminal and 3'-UTR region of GhCDKA cDNA (Supplementary Figure 1) was amplified by PCR with two primers CDKC-2 and CDK51 and used as a probe for Northern hybridization. Northern blotting had been performed three times, and the results were similar as shown in Figure 3(a), a $1.2 \mathrm{~kb}$ GhCDKA mRNA band was detected in all tissues. The GhCDKA transcript levels were high in 5 and 10 DPA fibers, moderate in 15 and 20 DPA fibers and roots, and low in flowers and leaves. The GhCDKA transcript level was also determined by RTPCR. As shown in Figure 3(b), the amounts of 618 bp PCR products amplified with the primers CDKC-2 and CDK5-1 were proportional to the first strand cDNA input. The RTPCR results indicated that transcript levels of the GhCDKA 


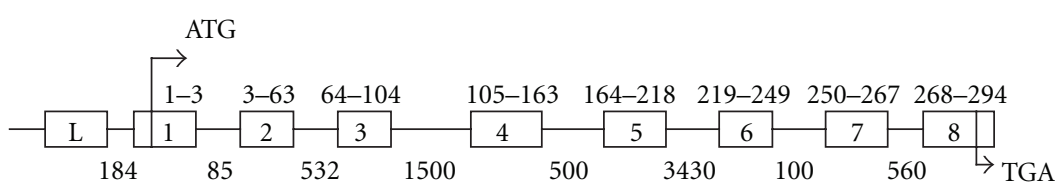

(a)

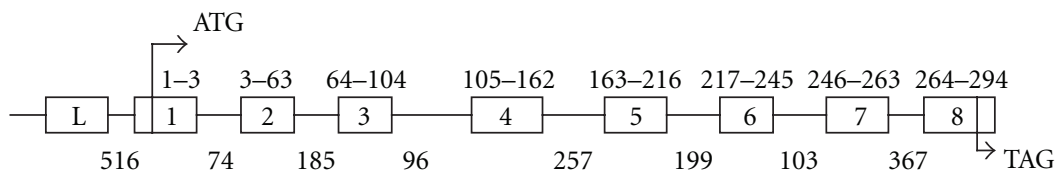

(b)

Figure 1: Diagrammatic comparison of cotton GhCDKA gene (a) with Arabidopsis thaliana AtCDKA; 1 Gene ((b), Genbank GI: 18408695). ATG represents the start codon. TGA and TAG are stop codons. The exons containing the coding regions are boxed (numbers 1-8). The exons located in the $5^{\prime}$-UTR region are represented by the L boxes. The positions of codons at the $5^{\prime}$ and $3^{\prime}$ ends within exons are indicated. Intron sizes are indicated under the intron lines.

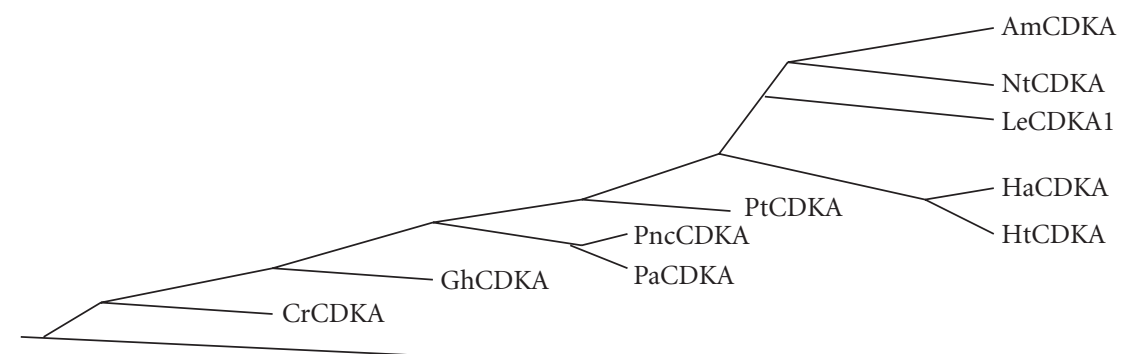

AtCDKA;1

\begin{tabular}{ll|l|l|l|l|l|}
\hline & 1 & & 1 & & & \\
10.7 & 10 & 8 & 6 & 4 & 2 & 0
\end{tabular}

Figure 2: Phylogenetic analysis of eleven plant CDKA proteins. The phylogenetic tree was constructed based on amino acidsequences of 11 plant CDKAs using the Clustal method. The eleven CDKA proteins are GhCDKA (Gossypium hirsutum); PtCDKA (Populus tremula $x$ Populus tremuloides); HaCDKA (Helianthus annuus); PaCDKA (Picea abies); LeCDKA1 (Solanum lycopersicum); PncCDKA (Pinus contorta); CrCDKA (Chenopodium rubrum); HtCDKA (Helianthus tuberosus); AmCDKA (Antirrhinum majus); NtCDKA (Nicotiana tobacum); AtCDKA; 1 (Arabidopsis thaliana).

gene were high in 5 and 10 DPA fibers, moderate in 15 DPA fibers and roots, and low in flowers and leaves. The RT-PCR result was consistent with Northern analyses.

Total protein isolated from 5, 10, 15, and 20 DPA cotton fibers, flowers, and leaves was separated by SDS-PAGE, electroblotted onto a nitrocellulose membrane, and probed with anti-PSTAIRE antibody. Western analysis showed that the antibody recognized a $34 \mathrm{kDa}$ protein in all cotton tissues (Figure 4). The GhCDKA protein was present in a moderate level in leaves but low in flowers. The GhCDKA protein in fibers increased from 5 DPA, peaked at 15 DPA, and decreased from 15 to 20 DPA. The Western and Northern results suggest that the GhCDKA gene is differentially expressed and developmentally regulated.

3.3. Identification of SNP in GhCDKA. Analyses of PCRamplified products from TM-1 (G. hirsutum), 3-79 (G. barbadense), CMD11 (G. tomentosum), CMD-5 (G. raimondii), and CMD-12 (G. mustellinum) by agarose gel electrophoresis revealed that the products were $0.9 \mathrm{~kb}$ in size and not discernibly polymorphic (data not shown). Genomic DNA of CMD-3 (G. arboreum) did not yield an amplified product with CDKA-specific primers, although this DNA was amplified with other control primers (unpublished information).

The $0.9 \mathrm{~kb} 5^{\prime}$ flanking sequence of the CDKA gene amplified from genomic DNA of CMD-01 (TM-1, G. hirsutum), CMD-02 (3-79, G. barbadense), and CMD-11 (G. tomentosum), respectively, was aligned with G. hirsutum var. DES 119 (Figure 5) for SNP identification. The incidence of SNP was about $1 \%$ in the -1 to -913 nt region of the CDKA gene. Specifically, we observed two indels, four transversions and three transitions type of mutation in the $5^{\prime}$ flanking sequences of the CDKA gene (Figure 5). Two SNP occurred between the two G. hirsutum genotypes and six SNP occurred between $G$. barbadense and $G$. hirsutum. Results suggested that a putative CDKA locus with at least four different haplotype variants was present in the tetraploid cotton species.

3.4. SNP Marker. To develop a primer for a potentially scorable SNP marker, we targeted a deletion $(G)$ site at nucleotide position 769 (Figure 5), as it distinguished the 


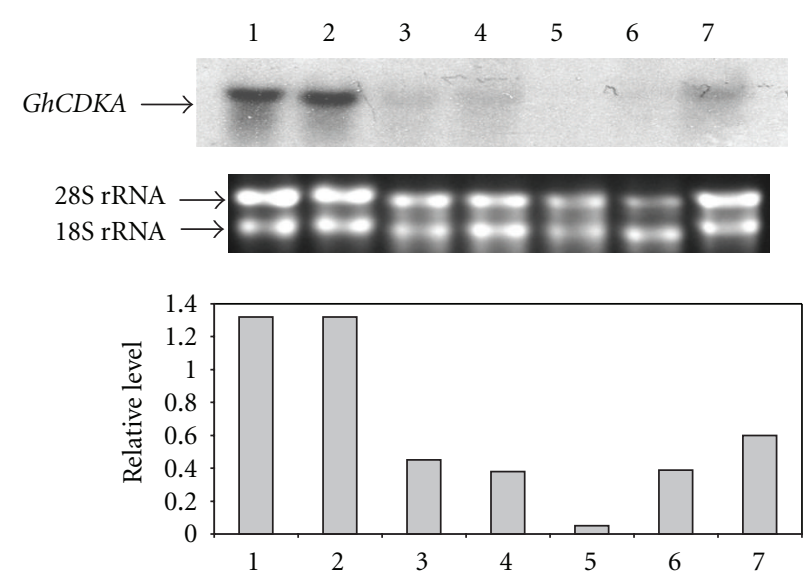

(a)

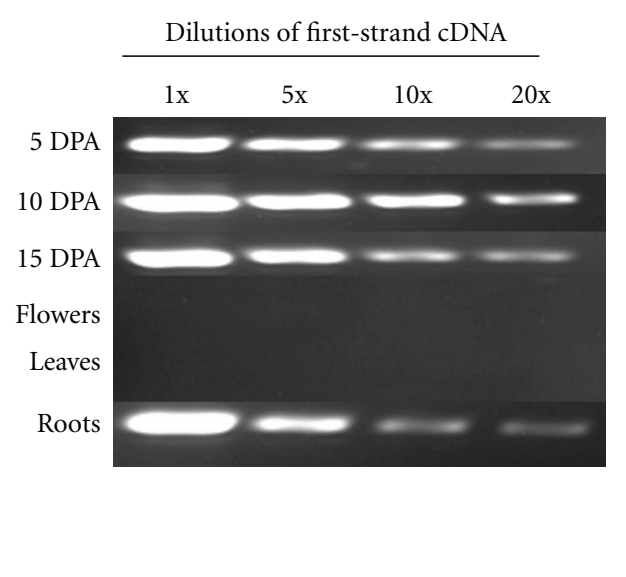

(b)

FIgURE 3: (a) Northern analysis of GhCDKA expression in different cotton tissues. Ten $\mu \mathrm{g}$ of total RNA from fibers (5, 10, 15, and 20 DPA, lanes 1-4), flowers (lane 5), leaves (lane 6), and roots (lane 7) was electrophoresed on an agarose gel, transferred onto a nylon membrane, and hybridized with a ${ }^{32} \mathrm{P}$-labeled GhCDKA cDNA. Two EtBr-stained rRNA bands indicate that an equal amount of total RNA was loaded for each sample. The relative GhCDKA transcript levels were determined by the ratio of hybridized intensity of the $1.2 \mathrm{~kb} G h C D K A$ mRNA to the EtBr stained 28S rRNA band using the program of Scion Image for Windows (Scion Corporation). (b) RT-PCR analysis of GhCDKA mRNA. Total RNA from leaves, flowers, roots, and 5, 10, and 15 DPA fibers was used as template in generating first strand cDNA. Each cDNA was made $1 \mathrm{x}, 5 \mathrm{x}, 10 \mathrm{x}$, and 20x dilutions and used as template for PCR amplification with two GhCDKA gene specific primers: CDKC-2 and CDK5-1.

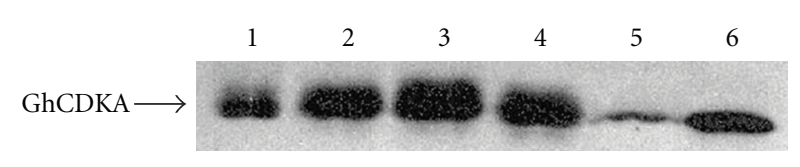

FIGURE 4: Western blot analysis of GhCDKA. Seventy $\mu \mathrm{g}$ of total protein was subjected to SDS-PAGE, blotted onto a nitrocellulose membrane, and probed with anti-PSTAIRE antibody. Proteins samples are from 5 DPA (lane 1), 10 DPA (lane 2), 15 DPA (lane 3), and 20 DPA (lane 4) fibers, flowers (lane 5), and leaves (lane 6).

3-79 CDKA sequence from those of the other tetraploids. The sequence of this specific SNP primer was $5^{\prime}$-GCCCAACTATAGAAATGAAA-3'. Two SNPs corresponding to the TM-1 (G. hirsutum) and 3-79 (G. barbadense) alleles were identified by the single primer extension technology and designated here as $C D K A^{c g}$ (black) and $C D K A^{\text {at }}$ (green) (Figure 6). $\mathrm{F}_{1}$ hybrids between TM-1 and 3-79 exhibited peaks of both alleles, showing codominance. Our results also detected the presence of $C D K A^{c g}$ allele in G. tomentosum and the presence of both $C D K A^{c g}$ and $C D K A^{\text {at }}$ alleles in the diploid species of G. raimondii (D5). We did not find the presence of any other bases except $G$ or $T$ as SNP markers specific to this SNP primer, suggesting that this locus was biallelic. We did not find the presence of any CDKAspecific SNP marker using the genomic DNA of G. arboreum (A2) species, suggesting the absence of any such locus in G. arboreum specific to the SNP primer or a major change in the primer annealing site of this marker in G. arboreum. This result was concordant with the absence of amplified products specific to CDKA gene in G. arboreum (A2) species, confirming the absence of the CDKA gene in G. arboreum (A2).
3.5. Chromosomal Location. Electropherograms revealed two peaks and thus heterozygosity for $C D K A^{a t}$ and $C D K A^{c g}$ alleles in all of the hypoaneuploid chromosome substitution $\mathrm{F}_{1}$ plants, except one (Figure 6). The single exception was the monotelodisomic Te16sh, which lacks all or most of the long arm of chromosome 16 and possessed the 3-79 allele, $C D K A^{\text {at }}$, but lacked the TM-1 allele, $C D K A^{c g}$. Similar results were observed for the disomic backcrossed chromosome 16 substitution line CSB 16 showing the presence of only the 379 alleles.

\section{Discussion}

As a first step toward understanding the mechanisms of fiber cell division and differentiation, a fiber CDNA, GhCDKA, and its corresponding gene have been cloned and characterized. The deduced aa sequence of GhCDKA shows high identity (more than 86\%) to the CDKAs from 10 diverse plant species. The alignment of the 11 plant CDKAs indicates that they all contain 294 aa residues (except for 302 aa in AmCDKA) and their three functional domains (ATPbinding, cyclin-binding, and catalytic) have identical aa sequences (data not shown). These results indicate that Atype CDKs are highly conserved in higher plants. Comparisons of the cotton CDKA gene with the Arabidopsis $c d c 2 \mathrm{~A}$ $(C D K A ; 1)$ gene revealed that both genes contain 7 introns within their ORFs (Figure 1). Although the two CDKA genes encode proteins with identical molecular mass, the intron sizes of the two genes are quite different. It will be interesting to examine whether there are any differences in transcriptional regulation or RNA splicing between the two genes. A genome-wide analysis of cell cycle genes indicated that a single CDKA gene (AtCDKA: 1) exists in Arabidopsis 


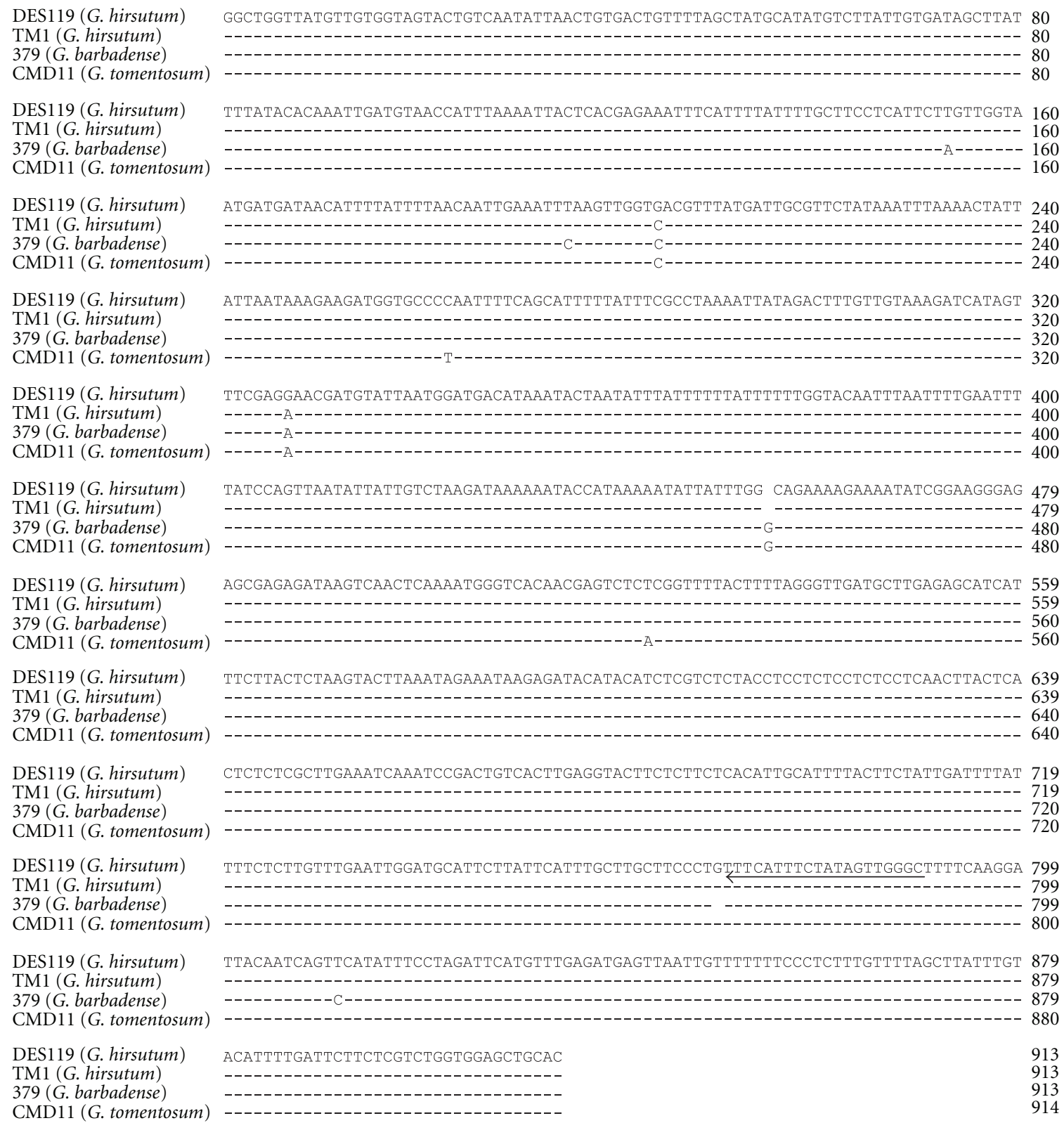

FIGURe 5: Alignment of 5' flanking sequences of CDKA gene of DES119 (G. hirsutum), TM-1 (G. hirsutum), 3-79 (G. barbadense), and CMD11 (G. tomentosum) showing the presence of several SNPs. The arrow indicated the position and the direction of the SNP primer specific to the CDKA gene.

thaliana [24]. In contrast, multiple copies of two genes (LeCDKA1 and LeCDKA2) encoding A-type CDKs have been found in tomato [25]. Nicotiana tabacum contains a single copy of the CDKA gene (NtCDKA) and at least one gene similar to NtCDKA in the genome [26]. In this study, Southern analysis revealed that one or two copies of the GhCDKA gene are present in cotton (Gossypium hirstum) (data not shown). Gossypium hirstum is a tetraploid plant which contains A and D genomes. Further work is needed to determine whether the GhCDKA gene is located in the A or $\mathrm{D}$ or both genomes.

The Arabidopsis and rice CDKA genes have been shown to be expressed not only in dividing tissues of root apex but also in differentiated tissues, such as, sclerenchyma, pericycle, and parenchyma of the vascular cylinder $[15,16]$. These results suggest that A-type CDKs are involved not only in cell division but also in cell differentiation which is important to the integration of cell division and differentiation in meristems to produce new organs during plant development. In contrast, no $c d c 2(C D K A)$ transcripts have been detected in differentiated adult tissues of chicken and Drosophila $[27,28]$. These findings suggest that plant CDKAs may have different functions from those of animals. The Arabidopsis $C D K A ; 1$ gene $(A t C D K A ; 1)$ has been shown to participate in trichome morphogenesis and development [29]. Fiber cells grown in planta do not divide after initiation; however, some 
AO Applied

GeneMapper v3.5

\begin{tabular}{|l|l|l|l|l|}
\hline Sample file & Sample name & Panel & OS & SQ \\
\hline \hline 1 01 TM 1-SNP F D25 A07 2004-11-19.fsa & 01 TM 1-SNP F D25 & None & & \\
\hline & 23 & 24 & 26 & 27 \\
\hline
\end{tabular}

\begin{tabular}{|c|c|c|c|c|c|c|}
\hline $102379 \mathrm{SNP}$ & 19.fsa & & & None & $\square$ & $\square$ \\
\hline 22 & 23 & 24 & 25 & 26 & 27 & 28 \\
\hline
\end{tabular}

\begin{tabular}{|c|cc|c|c|c|c|}
\hline $104 \mathrm{H} 4$ SNP F D30 D09 & 2004-11-19.fsa & & 04 H4 SNP F D30 & None & & \\
\hline 22 & 23 & 24 & 25 & 26 & 27 & 28 \\
\hline
\end{tabular}

\begin{tabular}{|c|c|c|c|c|c|}
\hline 109 CSB16 SNP F D30 A10 2004-11-19.fsa & 09 CSB16 SNP F D30 & None & & \\
\hline 22 & 23 & 24 & 25 & 26 & 27 \\
\hline
\end{tabular}

\begin{tabular}{|c|c|c|c|c|c|c|}
\hline $105 \mathrm{Tel6SH}$ & 19.fsa & & & None & 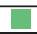 & 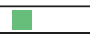 \\
\hline 22 & 23 & 24 & 25 & 26 & 27 & 28 \\
\hline
\end{tabular}

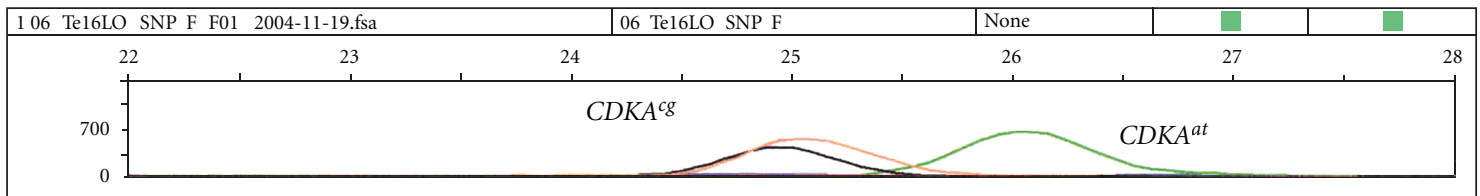

\begin{tabular}{|c|c|c|c|c|c|c|}
\hline $107 \mathrm{~A} 2$ SNP & 19.fsa & & & None & $\square$ & $\square$ \\
\hline 22 & 23 & 24 & 25 & 26 & 27 & 28 \\
\hline
\end{tabular}

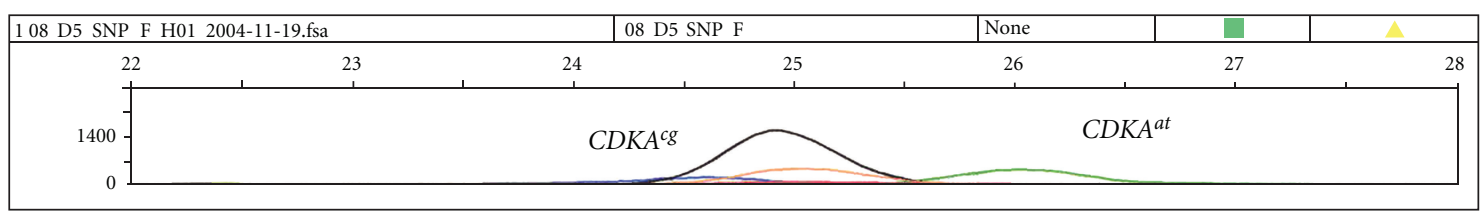

Figure 6: The electropherograms of two allelic SNPs, designated here as CDKA ${ }^{c g}$ (black) and CDKA ${ }^{a t}$ (green), that corresponded to the polymorphism between G. hirsutum inbred TM-1 and G. barbadense-doubled haploid 3-79. Genomic dosage profiles are shown for [A] TM-1; [B] 3-79; [C-E] three hypoaneuploid-interspecific G. hirsutum $x$ G. barbadense $\mathrm{F}_{1}$ hybrids, [C] lacking G. hirsutum chromosome 4 (H4), [D] a monotelodisomic-16sh F1 (Te16SH) lacking most of the long arm of G. hirsutum chromosome 16, [E] a monotelodisomic 16 Lo $\mathrm{F}_{1}$ (Te16LO) lacking most of the short arm of G. hirsutum chromosome-16; [F] a backcross disomic substitution plant (CSB-16) in which chromosome 16 of 3-79 has replaced the TM-1 chromosome 16; [G] a G. arboreum (A2 species); and [H] a G. raimondii plant (D5 species). Electropherograms revealing both peaks that indicate heterozygosity for both parental SNPs, as in the H4 interspecific F1 hybrid, indicate the locus is not in this chromosome. In contrast, absence of the G. hirsutum SNP CDKA ${ }^{c g}$ from CSB 16 and Te16SH hybrids and its presence in Te16LO concordantly indicate that the SNP marker is located in the long arm of the chromosome 16. 
fiber cells can divide under in vitro conditions [1]. These observations suggest that fiber cells retain the competence to divide after initiation. In this study, the GhCDKA gene has been shown to be strongly expressed in elongated fibers (Figure 3). Western analysis revealed that the fiber GhCDKA protein level increased from 5 DPA, peaked at $15 \mathrm{DPA}$, and remained at a high level at 20 DPA (Figure 4), which coincided with primary and secondary cell wall syntheses during fiber development. The expression analysis results suggest that GhCDKA may play a role in fiber development. The low GhCDKA transcript level versus the high amount of GhCDKA protein in 20 DPA fibers suggests the possible existence of posttranscriptional regulation of the GhCDKA gene. In Arabidopsis, the transcript and protein levels of AtCDKB; 1 (but not AtCDKA; 1) have been shown to correlate with cell division rate [30].

Duplications through polyploidization and/or segmental duplication and retrotransposon activity have contributed extensively to the extant genomes of the Malvaceae, including those of Gossypium [31-33]. The normal plant cell cycle process is distinguished by a $\mathrm{S}$ phase (a round of DNA replication) followed by $M$ phase which are separated by two gap phases (G1 and G2). Previous studies demonstrated that some plant cells followed a different cell cycle mode including endoreduplication where cells undergo iterative DNA replications without any subsequent cytokinesis [34]. Endoreduplication is usually considered to provide a mechanism for increasing cell size [35] and involved modulating the levels of CDKA activity [36, 37]. Cotton fibers are unique cells and they are differentiated from epidermal cells of the ovule. Regulation of cell cycle genes during the very early stages of fiber development triggered some specific epidermal cells in the ovule to stop cell division and then elongate into fiber cells. Previous experiments using 5-aminouracil (5-AU), an inhibitor of DNA replication, demonstrated that cotton fiber cells were arrested at the G1 stage [2]. Our results on Northern blot and RT-PCR analysis revealed that the GhCDKA transcript was high in 5-10 DPA fibers and moderate in 15 and 20 DPA fibers. Further studies are needed to reveal if GhCDKA is a regulator of cell cycle and DNA endoreduplication in fiber cells. Duplicated loci pose significant challenges in virtually all aspects of genomics research, including specific gene mapping in tetraploid cotton [23]. Locus-specific markers are thus particularly important for addressing these challenges, and the means to develop them are crucial to the advancement of structural genomics. One possible solution for marker development is to exploit sequence conservation of a specific gene and identify the gene in a locus-specific manner. The CDK gene is of special interest because of its possible importance to cotton fiber development, which entails major modifications of cell division and growth. Although cotton is clearly of polyploid origin, agarose gel analyses of amplified PCR product(s) from diverse taxa of cotton genomic DNAs using primers from conserved CDKA sequence regions showed no size polymorphisms. Such a result could be due to uniformity across duplicated loci or the existence of just one locus. The predicament had led us to seek SNP markers that could be used to define cotton $C D K$ gene(s) and alleles in a locusspecific manner. This approach may be generally applicable for SNP development in cotton and is of particular value for genes that are highly conserved.

Deficiency tests with interspecific hypoaneuploid F1s provide a quick and fairly robust means of localizing various types of loci to specific chromosomes and arms of cotton. When we examined the hypoaneuploid $\mathrm{F}_{1}$ hybrids used here, all but one exhibited a heterozygous banding pattern of $C D K A^{\text {at }}$ and $C D K A^{c g}$ alleles, suggesting that the $C D K A$ locus was in any of respective chromosomes or chromosome arms. However, although $C D K A^{\text {at }}$ was present in the monotelodisomic Te16Lo-interspecific hybrid, it was differentially absent from the quasi-isogenic Te16sh hybrid. These results concordantly localized the CDKA gene to the long arm of chromosome 16. In lieu of a monosomicinterspecific F1 hybrid, we examined DNA from a euploid disomic backcross $\left(\mathrm{BC}_{5} \mathrm{~S}_{n}\right)$ substitution line, CS-B16 [38]. The disomic chromosome substitution line is euploid but has one pair of chromosome 16 from $G$. barbadense line 3-79, whereas the other 25 chromosome pairs are largely or completely derived from TM-1. Accordingly, CS-B16 is expectedly devoided of TM-1 chromosome-16 alleles, homozygous for all loci in the alien (3-79) chromosome-16 and also homozygous for TM-1 alleles at nearly all ( 99\%) other loci of the genome. We observed that only the 3-79 $C D K A^{\text {at }}$ allele is present in CS-B16, strongly supporting the finding from the monotelodisomic interspecific F1 plants that the CDKA gene is located on chromosome 16. Our results on the chromosomal location of CDKA SNP marker on chromosome 16 were concordant with the cytogenetic evidence on the origin of chromosome 16 from an ancestral D genome diploid species [39].

The identification of SNP markers enables facile tracking of the CDKA gene in cotton, and this gene has been successfully mapped in the long arm of chromosome 16. Our results indicate that single-primer extension technology can be used to identify SNP markers in cotton genes, including the $5^{\prime}$-upstream region of the genes and thus facilitate the mapping and investigation of candidate genes for their effects on fiber development.

\section{Disclaimer}

Mention of trademark or proprietary product does not constitute a guarantee or warranty of the product by the United States Department of Agriculture and does not imply its approval to the exclusion of other products that may also be suitable. The nucleotide sequence of GhCDKA has been submitted to GenBank and assigned an accession number EU006765.

\section{Acknowledgments}

The authors appreciate the help of Mr. Douglas Dollar, Dr. Chuan Fu, and Ms. Lillie Hendrix, for assisting in the experiments. The authors also thank Drs. Rowena Kelly of USDA/ARS, Mississippi State, Ibrokhim Abdurakhmonov, 
Institute of Genetics and Plant Experimental Biology, Academy of Sciences of Uzbekistan, and Ramesh Kantety and Govind Sharma of Alabama A\&M University for their critical evaluation of the paper and helpful comments. The authors also acknowledge the financial help from Plant Genome program of USDA/NRI. This paper was approved for publication as no.12145 of Mississippi Agricultural and Forestry Experiment Station (MAFES).

\section{References}

[1] J. Van't Hof and S. Saha, "Cotton fibers can undergo cell division," American Journal of Botany, vol. 84, no. 9, pp. 12311235, 1997.

[2] S. Saha and J. Van't Hof, "Cotton fiber cells are arrested at G1 stage," Journal of New Seeds, vol. 7, no. 1, pp. 1-8, 2005.

[3] W. Dewitte and J. A. H. Murray, "The plant cell cycle," Annual Review of Plant Biology, vol. 54, pp. 235-264, 2003.

[4] D. Inzé and L. De Veylder, "Cell cycle regulation in plant development," Annual Review of Genetics, vol. 40, pp. 77-105, 2006.

[5] V. Mironov, L. De Veylder, M. Van Montagu, and D. Inzé, "Cyclin-dependent kinases and cell division in plants-the nexus," Plant Cell, vol. 11, no. 4, pp. 509-522, 1999.

[6] G. Wang, H. Kong, Y. Sun et al., "Genome-wide analysis of the cyclin family in arabidopsis and comparative phylogenetic analysis of plant cyclin-like proteins," Plant Physiology, vol. 135, no. 2, pp. 1084-1099, 2004.

[7] J. A. Torres Acosta, J. de Almeida Engler, J. Raes et al., "Molecular characterization of Arabidopsis PHO80-like proteins, a novel class of CDKA;1-interacting cyclins," Cellular and Molecular Life Sciences, vol. 61, no. 12, pp. 1485-1497, 2004.

[8] J. Joubès, C. Chevalier, D. Dudits et al., "CDK-related protein kinases in plants," Plant Molecular Biology, vol. 43, no. 5-6, pp. 607-620, 2000.

[9] B. Ducommun, P. Brambilla, M. A. Felix, B. R. Franza, E. Karsenti Jr., and G. Draetta, "Cdc2 phosphorylation is required for its interaction with cyclin," EMBO Journal, vol. 10, no. 11, pp. 3311-3319, 1991.

[10] J. Colasanti, M. Tyers, and V. Sundaresan, "Isolation and characterization of cDNA clones encoding a functional p34cdc2 homologue from Zea mays," Proceedings of the National Academy of Sciences of the United States of America, vol. 88, no. 8, pp. 3377-3381, 1991.

[11] P. C. Ferreira, A. S. Hemerly, R. Villarroel, M. Van Montagu, and D. Inzé, "The Arabidopsis functional homolog of the p34cdc2 protein kinase," Plant Cell, vol. 3, no. 5, pp. 531-540, 1991.

[12] T. Hirayama, Y. Imajuku, T. Anai, M. Matsui, and A. Oka, "Identification of two cell-cycle-controlling cdc2 gene homologs in Arabidopsis thaliana," Gene, vol. 105, no. 2, pp. 159165, 1991.

[13] H. Hirt, A. Páy, L. Bögre, I. Meskiene, and E. Heberle-Bors, "Cdc2MsB, a cognate $c d c 2$ gene from alfalfa, complements the G1/S but not the G2/M transition of budding yeast cdc28 mutants," Plant Journal, vol. 4, no. 1, pp. 61-69, 1993.

[14] Z. Magyar, T. Mészáros, P. Miskolczi et al., "Cell cycle phase specificity of putative cyclin-dependent kinase variants in synchronized alfalfa cells," Plant Cell, vol. 9, no. 2, pp. 223 235, 1997.
[15] M. Umeda, C. Umeda-Hara, M. Yamaguchi, J. Hashimoto, and H. Uchimiya, "Differential expression of genes for cyclindependent protein kinases in rice plants," Plant Physiology, vol. 119, no. 1, pp. 31-40, 1999.

[16] A. S. Hemerly, P. Ferreira, J. De Almeida Engler, M. Van Montagu, G. Engler, and D. Inze, "Cdc2a expression in Arabidopsis is linked with competence for cell division," Plant Cell, vol. 5, no. 12, pp. 1711-1723, 1993.

[17] M. Yamaguchi, H. Kato, S. Yoshida, S. Yamamura, H. Uchimiya, and M. Umeda, "Control of in vitro organogenesis by cyclin-dependent kinase activities in plants," Proceedings of the National Academy of Sciences of the United States of America, vol. 100, no. 13, pp. 8019-8023, 2003.

[18] S. Adachi, N. Nobusawa, and M. Umeda, "Quantitative and cell type-specific transcriptional regulation of A-type cyclindependent kinase in Arabidopsis thaliana," Developmental Biology, vol. 329, no. 2, pp. 306-314, 2009.

[19] R. L. Barent and T. E. Elthon, "Two-dimensional gels: an easy method for large quantities of proteins," Plant Molecular Biology Reporter, vol. 10, no. 4, pp. 338-344, 1992.

[20] J. Z. Yu, R. Cantrell, R. Kohel et al., "Establishment of the standardized cotton microsatellite database (CMD) panel," in Proceedings of the Beltwide Cotton Improvement Conference, pp. 5-8, National Cotton Council, San Antonio, Tex, USA, January 2004.

[21] S. Liu, S. Saha, D. Stelly, B. Burr, and R. G. Cantrell, "Chromosomal assignment of microsatellite loci in cotton," Journal of Heredity, vol. 91, no. 4, pp. 326-331, 2000.

[22] S. Saha, J. Wu, J. N. Jenkins et al., "Effect of chromosome substitutions from Gossypium barbadense L. 3-79 into G. hirsutum L. TM-1 on agronomic and fiber traits," Journal of Cotton Science, vol. 8, no. 3, pp. 162-169, 2004.

[23] Z. T. Buriev, S. Saha, I. Y. Abdurakhmonov et al., "Clustering, haplotype diversity and locations of $M I C-3$ : a unique rootspecific defense-related gene family in Upland cotton (Gossypium hirsutum L.)," Theoretical and Applied Genetics, vol. 120, no. 3, pp. 587-606, 2010.

[24] K. Vandepoele, J. Raes, L. De Veylder, P. Rouzé, S. Rombauts, and D. Inzé, "Genome-wide analysis of core cell cycle genes in Arabidopsis," Plant Cell, vol. 14, no. 4, pp. 903-916, 2002.

[25] J. Joubès, T. H. Phan, D. Just et al., "Molecular and biochemical characterization of the involvement of cyclin-dependent kinase a during the early development of tomato fruit," Plant Physiology, vol. 121, no. 3, pp. 857-869, 1999.

[26] Y. Y. Setiady, M. Sekine, N. Hariguchi, H. Kouchi, and A. Shinmyo, "Molecular cloning and characterization of a cDNA clone that encodes a Cdc2 homolog from Nicotiana tabacum," Plant and Cell Physiology, vol. 37, no. 3, pp. 369-376, 1996.

[27] W. Krek and E. A. Nigg, "Structure and developmental expression of the chicken CDC2 kinase," EMBO Journal, vol. 8, no. 10, pp. 3071-3078, 1989.

[28] C. F. Lehner and P. H. O'Farrell, "Drosophila cdc2 homologs: a functional homolog is coexpressed with a cognate variant," EMBO Journal, vol. 9, no. 11, pp. 3573-3581, 1990.

[29] Y. Imajuku, Y. Ohashi, T. Aoyama, K. Goto, and A. Oka, "An upstream region of the Arabidopsis thaliana CDKA;1 (CDC2aAt) gene directs transcription during trichome development," Plant Molecular Biology, vol. 46, no. 2, pp. 205-213, 2001.

[30] C. Richard, C. Granier, D. Inzé, and L. De Veylder, "Analysis of cell division parameters and cell cycle gene expression during the cultivation of Arabidopsis thaliana cell suspensions," Journal of Experimental Botany, vol. 52, no. 361, pp. 1625-1633, 2001. 
[31] G. Moore, "Cereal chromosome structure, evolution, and pairing," Annual Review Plant Physiology and Plant Molecular Biology, vol. 51, pp. 195-222, 2000.

[32] M. Thangavelu, A. B. James, A. Bankier, G. J. Bryan, P. H. Dear, and R. Waugh, "Happy mapping in plant genome: reconstruction and analysis of a high-resolution physical map of a 1.9 Mbp region of Arabidopsis thaliana chromosome 4," Plant Biotechnology Journal, vol. 1, no. 1, pp. 23-31, 2003.

[33] B. E. Pfeil, C. L. Brubaker, L. A. Craven, and M. D. Crisp, "Paralogy and orthology in the malvaceae rpb2 gene family: Investigation of gene duplication in Hibiscus," Molecular Biology and Evolution, vol. 21, no. 7, pp. 1428-1437, 2004.

[34] J. T. Leiva-Neto, G. Grafi, P. A. Sabelli et al., "A dominant negative mutant of cyclin-dependent kinase A reduces endoreduplication but not cell size or gene expression in maize endosperm," Plant Cell, vol. 16, no. 7, pp. 1854-1869, 2004.

[35] K. Sugimoto-Shirasu and K. Roberts, "Big it up: endoreduplication and cell-size control in plants," Current Opinion in Plant Biology, vol. 6, no. 6, pp. 544-553, 2003.

[36] B. A. Larkins, B. P. Dilkes, R. A. Dante, C. M. Coelho, Y. M. Woo, and Y. Liu, "Investigating the hows and whys of DNA endoreduplication," Journal of Experimental Botany, vol. 52, no. 355, pp. 183-192, 2001.

[37] N. Gonzalez, F. Gévaudant, M. Hernould, C. Chevalier, and A. Mouras, "The cell cycle-associated protein kinase WEE1 regulates cell size in relation to endoreduplication in developing tomato fruit," Plant Journal, vol. 51, no. 4, pp. 642-655, 2007.

[38] D. M. Stelly, S. Saha, D. A. Raska, J. N. Jenkins, J. C. McCarty Jr., and O. A. Gutiérrez, "Registration of 17 upland (Gossypium hirsutum) cotton germplasm lines disomic for different $G$. barbadense chromosome or arm substitutions," Crop Science, vol. 45, pp. 2663-2665, 2005.

[39] J. E. Endrizzi, E. L. Turcotte, and R. J. Kohel, "Quantitative genetics, cytology and cytogenetics," in Cotton, R. J. Kohel and C. F. Lewis, Eds., pp. 81-129, American Society of Agronomy, Madison, Wis, USA, 1984. 

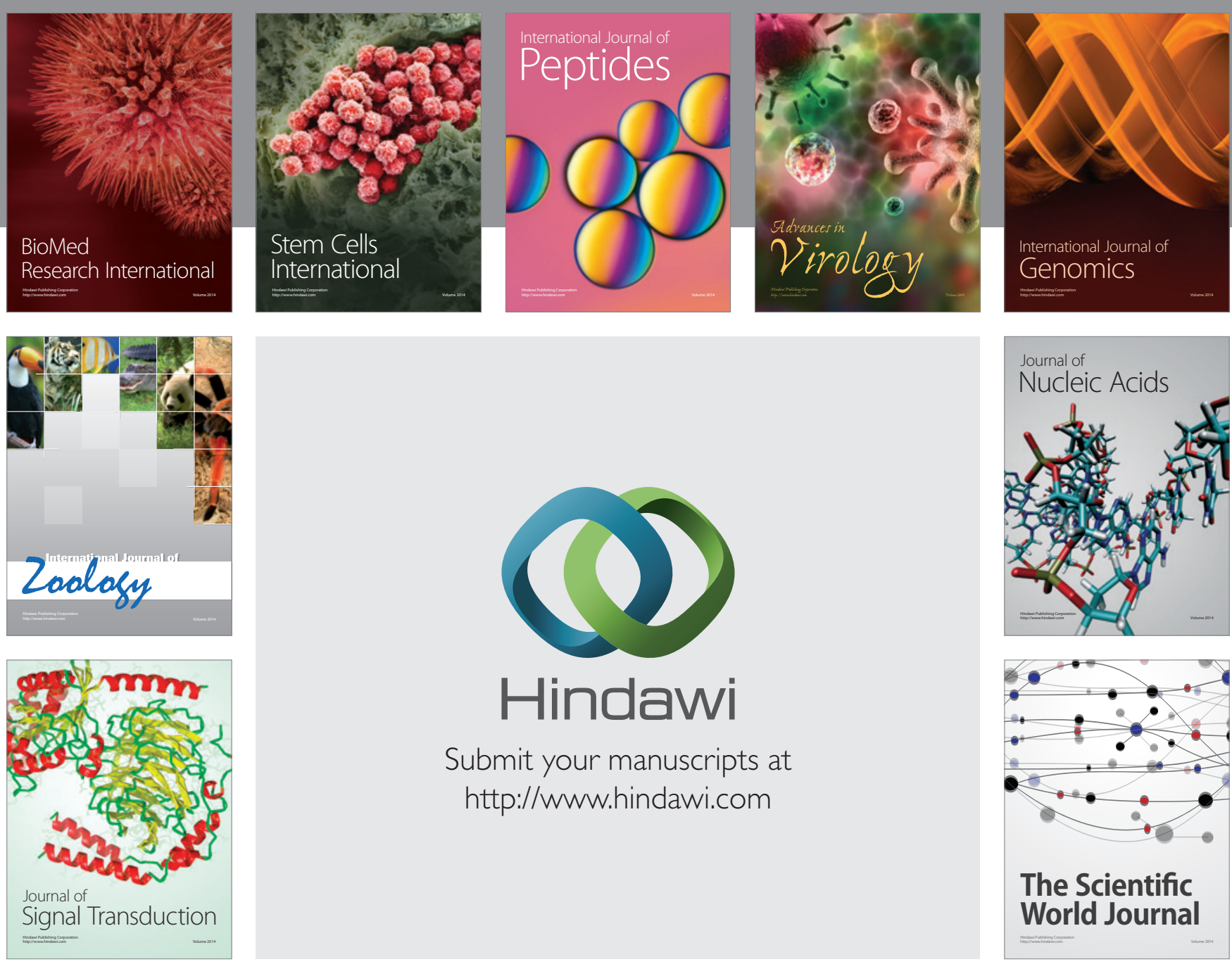

Submit your manuscripts at

http://www.hindawi.com
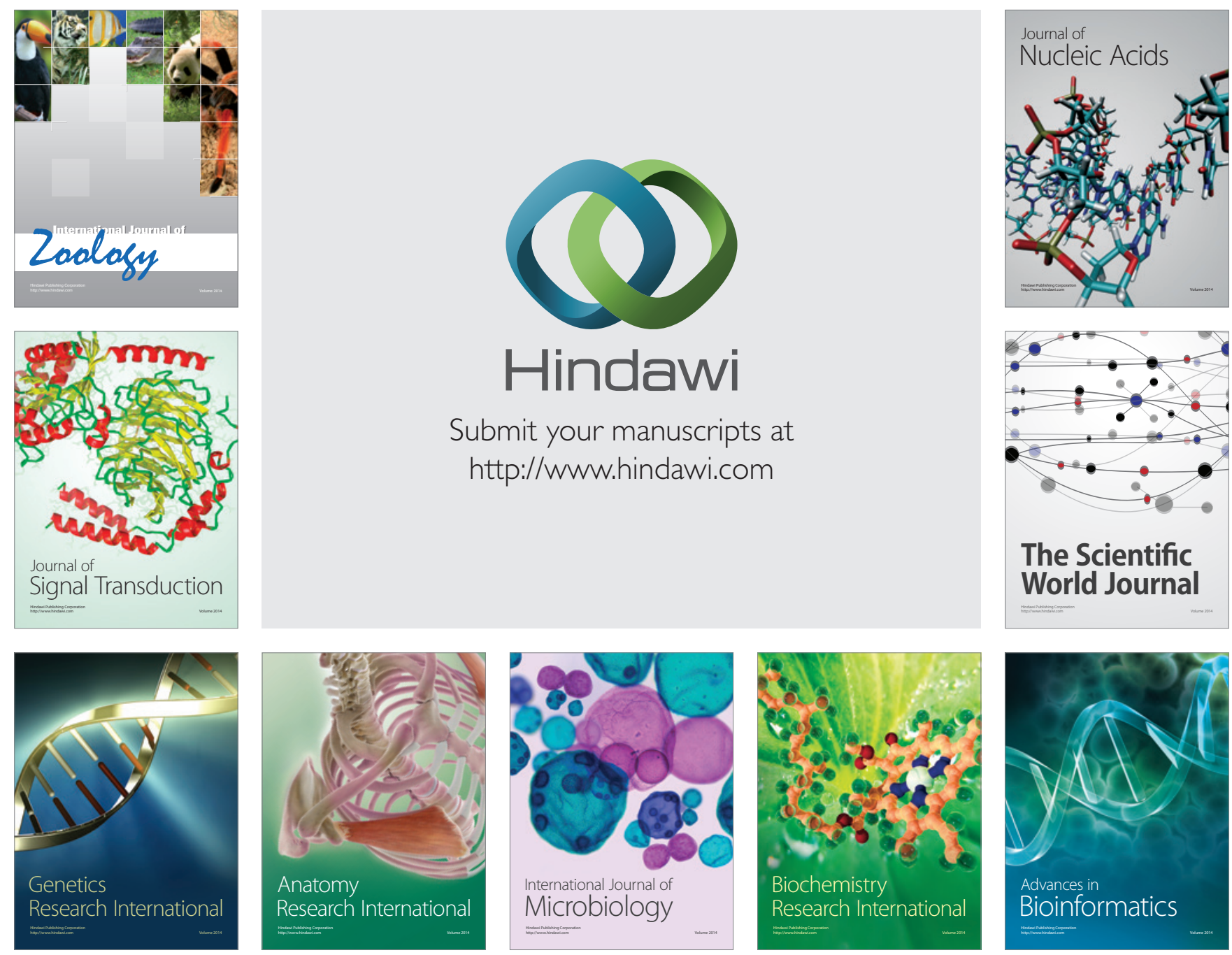

The Scientific World Journal
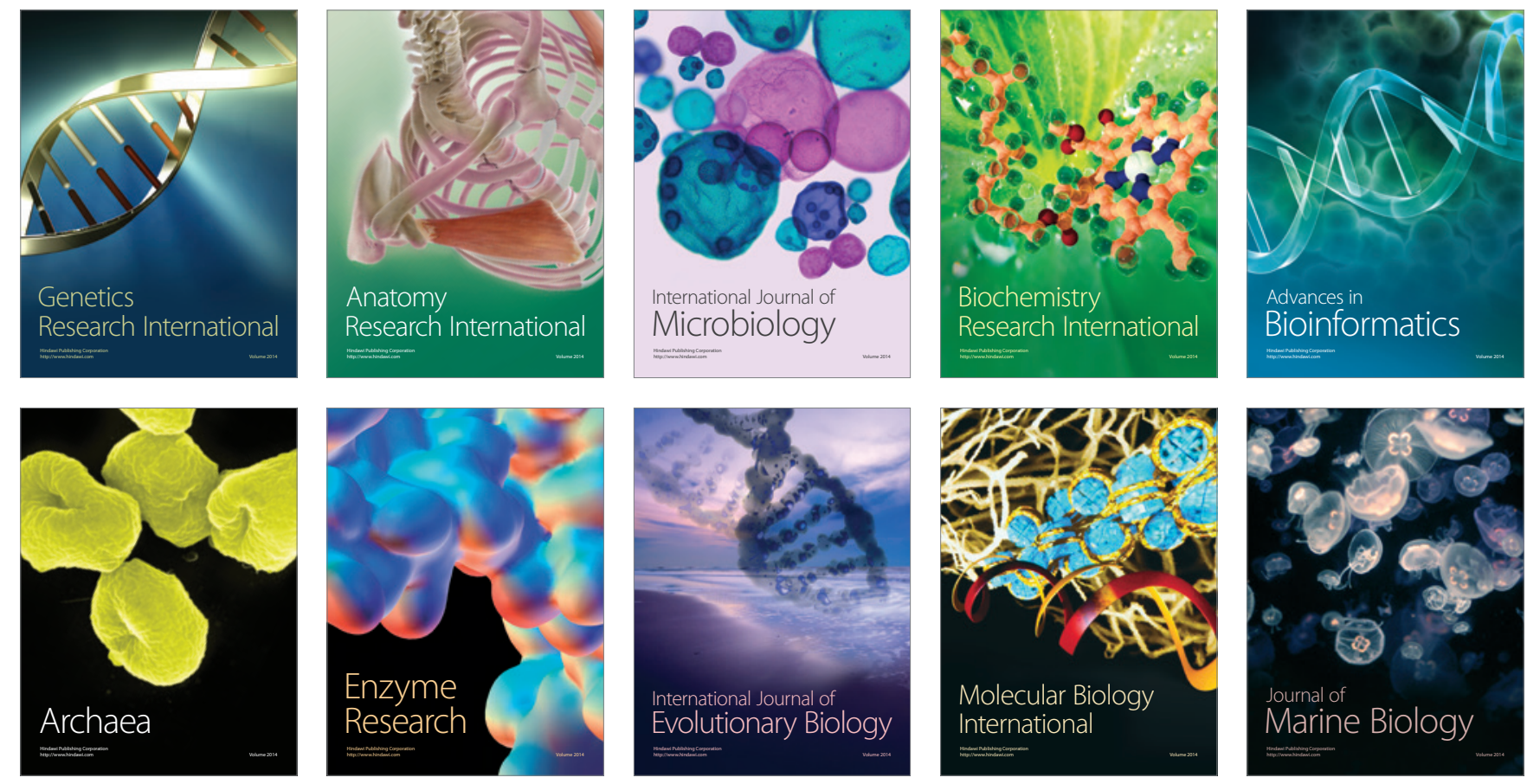